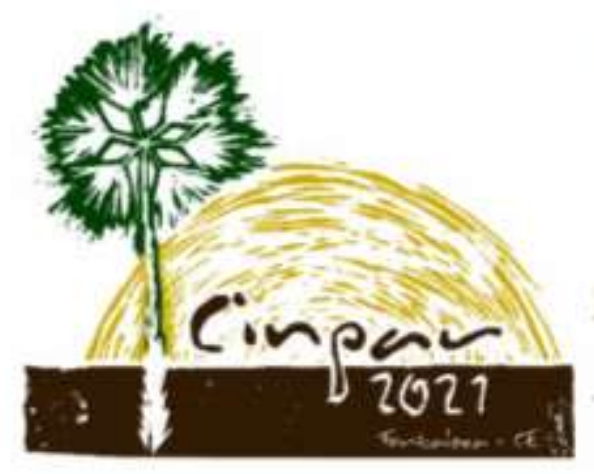

XVII Congresso Internacional sobre Patologia e Reabilitação das Construções

XVII Congreso Internacional sobre Patologia y Rehabilitación de las Construcciones

XVII International Conference on Pathology and Constructions Rehabilitation

FORTALEZA (Brasil), 3 a 5 de junho de 2021 https://doi.org/10.4322/CINPAR.2021.059

\title{
Análise de Manifestações Patológicas e de Estruturas de Concreto Armado para Preservação do Patrimônio - Museu da Cidade - Brasília-DF
}

\section{Analysis of Pathological Manifestations and Reinforced Concrete Structures for Heritage Preservation - Museu da Cidade - Brasília-DF}

\author{
Leonardo INOJOSA ${ }^{1}$, João da Costa PANTOJA ${ }^{2}$, Márcio Augusto Roma BUZAR ${ }^{3}$, Iberê Pinheiro de OLIVEIRA

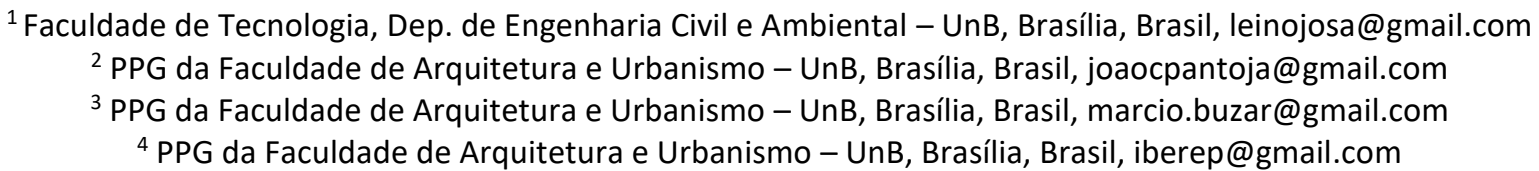

Resumo: O Museu da Cidade ou Museu Histórico de Brasília, é o museu mais antigo da capital, foi inaugurado em 21 de Abril de 1960, mesma data da inauguração da cidade, representa a transferência oficial da capital do Rio de Janeiro para Brasília. O Museu está localizado na Praça dos Três Poderes. O projeto, de 1958, é de Oscar Niemeyer, com influência do modernismo europeu de Le Crobusier, foi construído para registrar a construção de Brasília. O edifício foi tombado pelo Governo do Distrito Federal em 1982 IPHAN em 2007. 0 Museu está contido em um bloco longitudinal de concreto armado de 5,00 $\mathrm{m} \times 35,00 \mathrm{~m}$, formado por 2 vigas em C. O bloco se apoia em um cubo que, formado por 2 pilares, abriga a escada de acesso e serviços. A composição do aparente monolito, apoiado sobre um único suporte, gera dois balanços expressivos. A edificação é revestida em mármore branco. Em suas fachadas são esculpidos textos referentes a fatos relevantes para a construção de Brasília, além de uma escultura da cabeça de JK esculpida por José Alves Pedrosa, em pedra-sabão, com 1,5 Ton. Internamente, o espaço expositivo interno apresenta 16 painéis, também gravados no mármore, com citações sobre a transferência e construção da Nova Capital. Este trabalho identificou, através de inspeções visuais diversas manifestações patológicas no Museu, como fissuras, fraturas, lascagens, infiltrações, infiltrações, etc que foram classificadas segundo a metodologia GUT para identificar as prioridades de intervenções. Além disso, foi desenvolvido um modelo de análise estrutural através do método de elementos finitos para avaliar o desempenho e o comportamento estrutural do monumento.

Palavras-chave: Concreto armado, Manifestações patológicas, reabilitação de estruturas.

Abstract: The City Museum or Historical Museum of Brasilia is the oldest museum in the capital, it was inaugurated on April 21, 1960, the same date of the inauguration of the city, it represents the official transfer of the capital from Rio de Janeiro to Brasilia. The Museum is located at Praça dos Três Poderes. The project, dated of 1958, by Oscar Niemeyer, influenced by Le Crobusier's European modernism, was built to register the construction of Brasilia. The Government of the Federal District in 1982 and IPHAN in 2007 listed the building as historical heritage. The Museum is contained in a longitudinal block of reinforced concrete of 5.00 $m \times 35.00 \mathrm{~m}$, formed by 2 beams in C shape. The block is supported on a cube that, formed by two pillars, houses the access staircase and services area. The composition of the apparent monolith, supported on a single support, generates two expressive balances. The building is covered in white marble. Three texts are sculpted on its façades - on the east facade, visible from the center of the square, a sentence by Juscelino Kubischeck, on the base of the building, relevant facts for the construction of Brasilia and next to the sculpture of the head of JK sculpted by José Alves Pedrosa, in soapstone, with $1.5 \mathrm{t}$, a phrase in honor of the president. 
Internally, the exhibition space features 16 panels, also engraved in marble, with quotes about the transfer and construction of the new capital. This work identified, through visual inspections, several pathological manifestations in the Museum, such as cracks, fractures, chipping, infiltrations, infiltrations, etc. that were classified according to the GUT methodology to identify the intervention priorities. In addition, a structural analysis model was developed using the finite element method to assess the performance and structural behavior of the monument.

Key-words: Reinforced concrete, Pathological manifestations, rehabilitation of structures.

\section{Introdução}

O Museu da Cidade, também conhecido como Museu Histórico de Brasília está localizado na Praça dos Três Poderes, em local privilegiado do centro cívico da capital do Brasil, próximo ao limite da praça com a via transversal ao Eixo Monumental, se situando entre os principais edifícios da cidade - Palácio do Planalto, Congresso Nacional e Supremo Tribunal Federal.

Museu da Cidade, ou Museu Histórico de Brasília (Figura 1), é uma edificação em forma de "um pequeno monumento que contém um ambiente penetrável", projetada e, 1958 pelo Arquiteto Oscar Niemayer como um "Lugar de Memória" (Soares, 2017). Foi inaugurado em 21 de abril de 1960, mesma data da inauguração da cidade, tornando-se o museu mais antigo da capital e representando a transferência oficial da Capital Federal do Rio de Janeiro para Brasília.

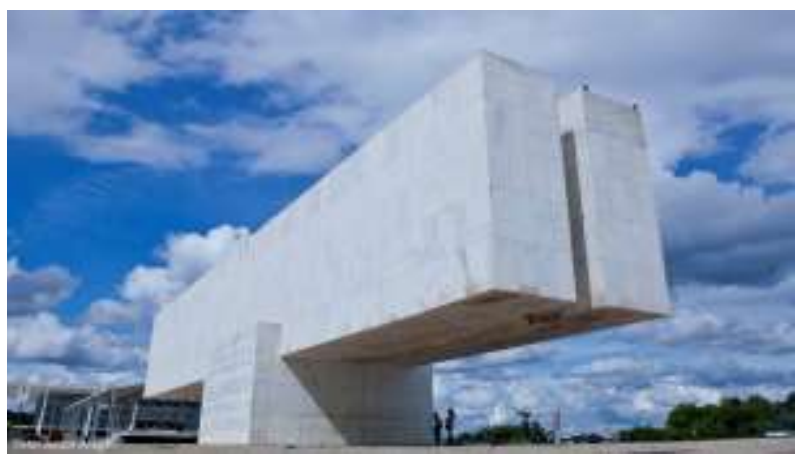

Figura 1 - Museu da Cidade, ou Museu Histórico de Brasília (foto de Júnior Aragão - creative commons).

O Museu da Cidade, ao ser projetado e inaugurado junto com os principais monumentos de Brasília, tais como a Catedral, o Teatro Nacional, a Igrejinha Nossa Senhora de Fátima, além dos já citados edifícios da Praças dos Três Poderes, revela a importância do monumento e de seu conteúdo - a história da construção de Brasília, registrada em suas próprias paredes - para as pessoas que ajudaram a erguer a nova capital.

O edifício é formado por dois volumes, uma base de apoio e acesso e um grande monólito que abriga o salão do museu, e assim é descrito por Niemeyer: "A forma plástica desse monumento, exprimindo por seu arrojo as possibilidades do concreto armado, atende, também, as características procuradas de sobriedade e beleza" (Niemeyer, 1959, p. 36 apud Soares, 2017). Essa composição é "uma clara referência à ideia de Le Corbusier para o monumento em homenagem a Paul Vaillant" (Lauande, 2010).

O edifício foi tombado pelo Governo do Distrito Federal em 1982 (decreto no 6.718) e pelo Instituto do Patrimônio Histórico e Artístico Nacional (IPHAN) em 2007 (Processo 1550-T-07). Mesmo assim, segundo o próprio IPHAN (2009) o museu faz parte de um conjunto de edifícios da época que "nem possuem projetos, mas apenas desenhos", o que dificulta a pesquisa e memória do monumento.

A edificação é revestida em mármore branco de Cachoeiro do Itapemerim. Em suas fachadas são esculpidos três textos. Na Fachada Leste, visível do centro da Praça está gravada uma frase de Juscelino Kubischeck.

Na base do edifício, fatos relevantes para a construção de Brasília. Também voltada para a Praça dos Três Poderes, junto a escultura da cabeça de Juscelino Kubitschek por José Alves Pedrosa, em pedra-sabão, com $1,5 t$, uma frase em homenagem ao presidente.

Internamente, o espaço expositivo apresenta 16 painéis gravados no mármore, com citações sobre a transferência e construção da Nova Capital. 


\section{Estrutura}

O Museu está contido em um bloco longitudinal de concreto armado de 5,00 $\mathrm{m} \times 35,00 \mathrm{~m}$, formado por 2 vigas em $\mathrm{C}$. O bloco se apoia em um cubo que, formado por 2 pilares, abriga a escada de acesso, além de pequeno depósito e sanitário de acesso restrito aos funcionários. O vão, situado na parte superior, entre as duas vigas, serviria como iluminação, porém, hoje, esse recurso não é utilizado. Nota-se na Figura 2 que a composição do monolito, aparentemente apoiado sobre um único suporte, gera dois balanços expressivos.

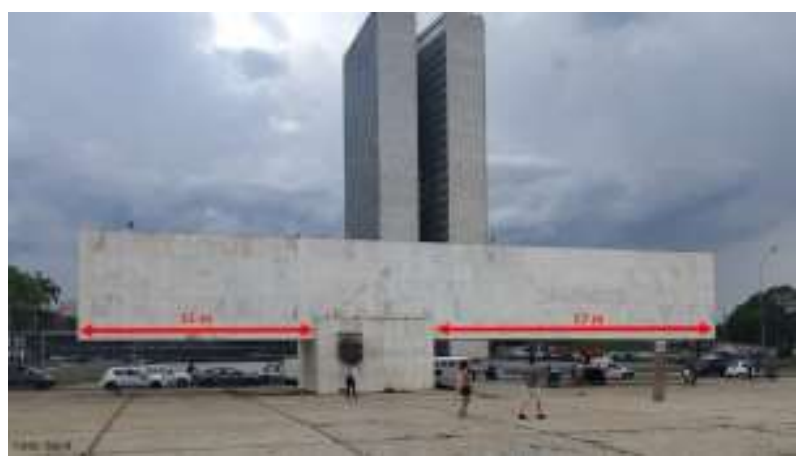

Figura 2 - Museu da Cidade, balanços expressivos

\subsection{Análise da Estrutura}

Devido à falta de projetos do museu, citada anteriormente, o levantamento das dimensões do edifício foi baseado em desenhos e imagens, atuais e registradas em publicações da época, como a revista Módulo, foi possível identificar as principais peças estruturais conforme Quadro 1, utilizadas para fazer a modelagem da estrutura no programa SAP 2000, versão 21, conforme ilustrada na Figura 3. A modelagem foi feita utilizando elementos tipo frame (barras), considerando o perfil " $\mathrm{C}$ " de cada viga principal e as dimensões encontradas para os 2 pilares que formam a base do sistema estrutural.

As cargas utilizadas no modelo foram inseridas de acordo com o estabelecido nas normas ABNT NBR 6118:2014 e 6120:2017 para o peso próprio da estrutura de concreto armado $\left(25 \mathrm{kN} / \mathrm{m}^{3}\right)$ e revestimentos em mármore $\left(0,85 \mathrm{KN} / \mathrm{m}^{2}\right)$, além da carga acidental indicada para áreas de exposição $\left(5 \mathrm{~N} / \mathrm{m}^{2}\right)$.

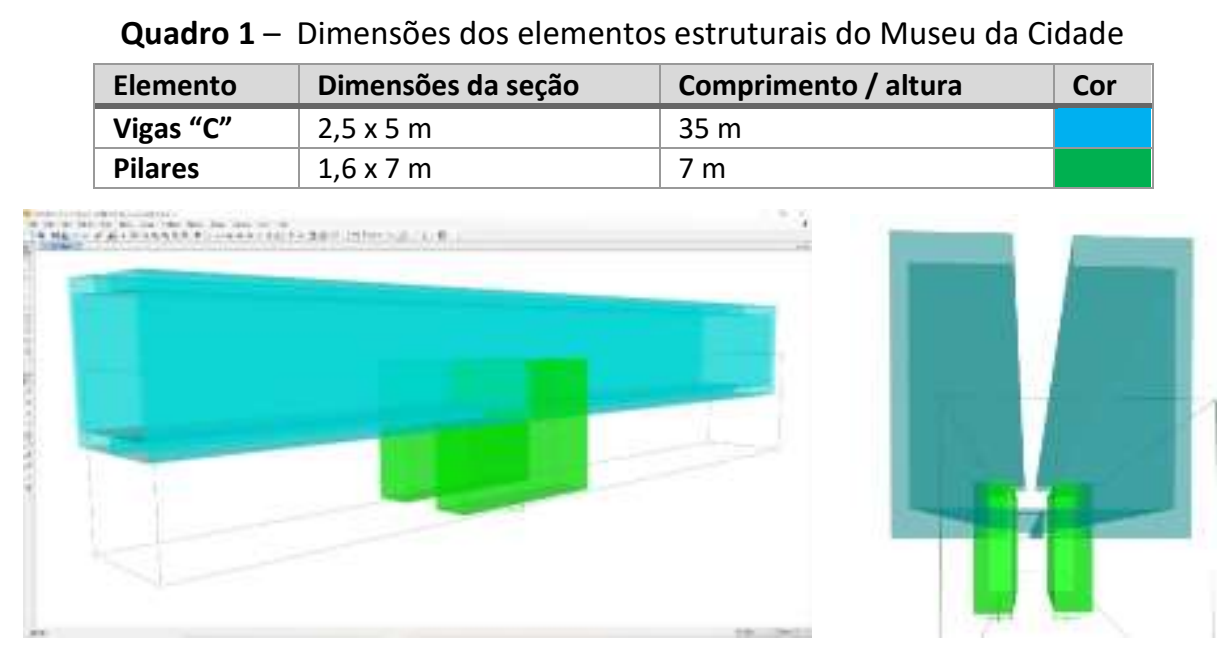

Figura 3 - Modelo estrutural. Desenvolvido pelos autores (SAP 200 v.21)

$\mathrm{Na}$ análise dos deslocamentos na estrutura, foi utilizada a combinação de carga para o Estado Limite de Serviço (ELS) (Equação 1). Já para a análise de esforços e dimensionamento foi utilizada a combinação de carga para Estado Limite Último (ELU), mostrado na Equação 2, conforme a ABNT NBR 6118:2014.

$$
\begin{gathered}
(1 \times g)+(1 \times q) \\
(1,4 \times g)+(1,5 \times q)
\end{gathered}
$$

Onde:

$\mathrm{g}=$ Cargas Permanentes e $\mathrm{q}=$ Cargas Acidentais 
A Figura 4 apresenta os deslocamentos nas extremidades da viga " $\mathrm{C}$ " que forma o bloco principal do Museu da Cidade. Nota-se que o deslocamento máximo, na extremidade do maior balanço é de aproximadamente $1 \mathrm{~cm}$, valor bem abaixo do que o máximo permitido pela norma atual (I/350).

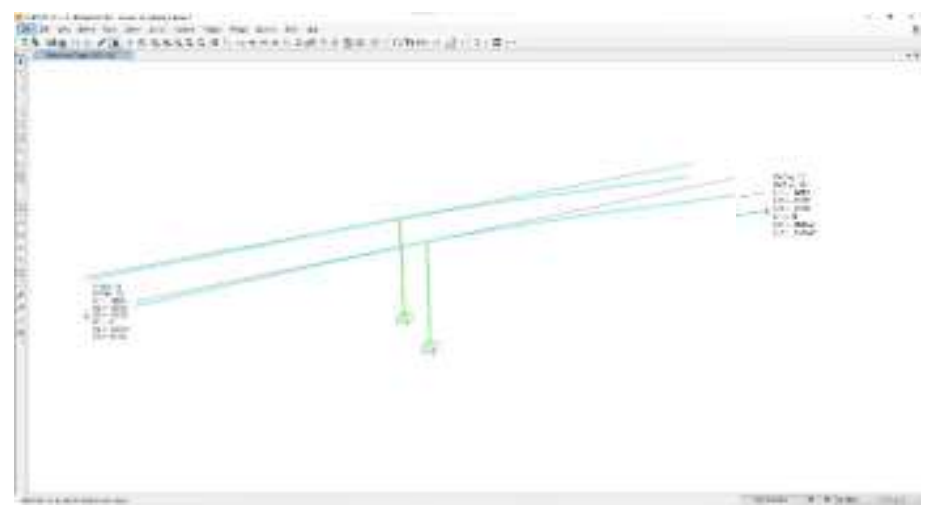

Figura 4 - Gráfico de deslocamentos para o Museu da Cidade. Desenvolvido pelos autores (SAP 200 v.21)

A Figura 5 mostra o diagrama de momentos fletores nas vigas " $C$ ", conforme esperado, a concentração de momento ocorre no encontro das vigas com o pilar de apoio, onde o momento chega a $30.517 \mathrm{KN}$.m. Já a Figura 6 mostra o diagrama de força axial nos pilares da base do museu. Percebe-se um esforço máximo na base dos pilares de $-7115 \mathrm{KN}$.

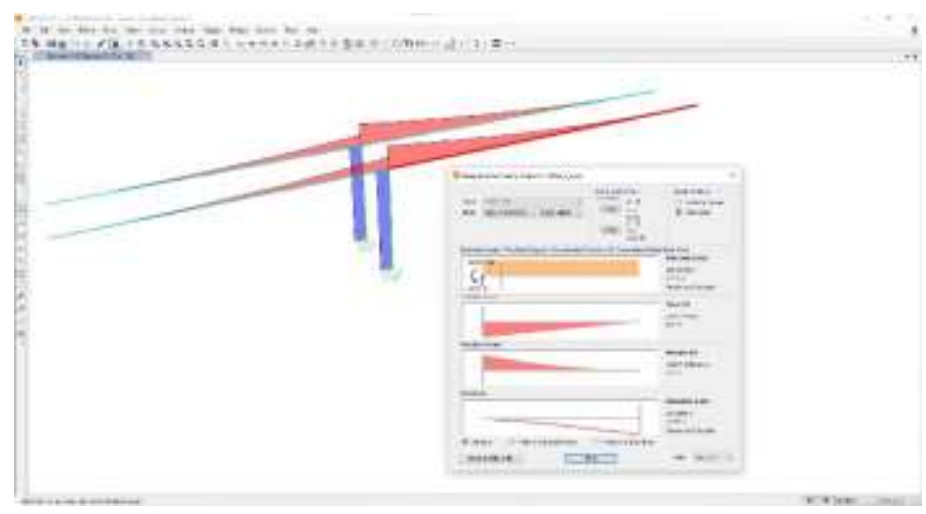

Figura 5 - Diagramas de momentos Fletores e gráficos de esforços na viga " $\mathrm{C}$ " do Museu da Cidade. Desenvolvido pelos autores (SAP 200 v.21)

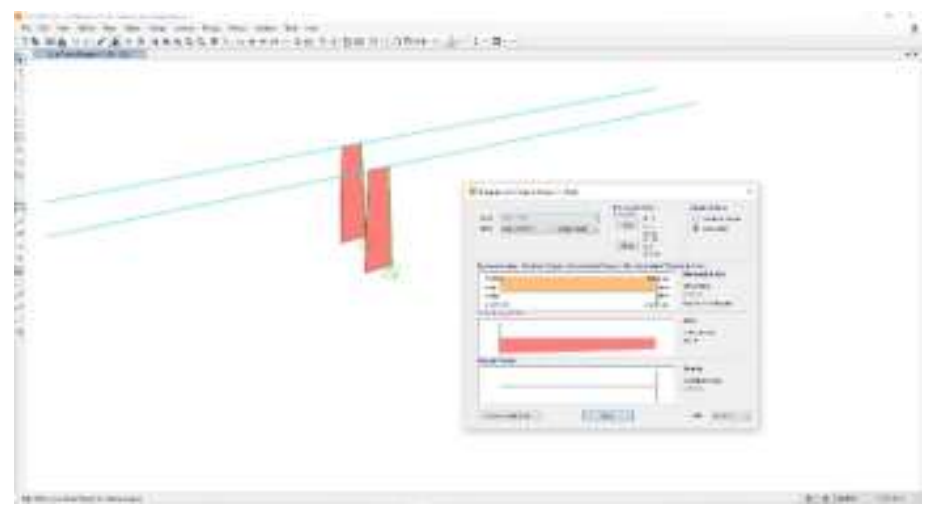

Figura 6 - Diagramas de esforço axial nos pilares do Museu da Cidade. Desenvolvido pelos autores (SAP 200 v.21)

Os dados analisados demonstram que as peças estruturais do edifício do Museu da Cidade são de dimensões maiores que as mínimas exigidas pelas normas atuais nas condições levantadas.

\section{Inspeção Predial}


Segundo a ABNT NBR-16747:2020, as inspeções visuais fornecem a perspectiva qualitativa do dano e podem aferir os agentes de degradação de acordo com fatores endógenos como comportamento de uso e mesmo exógenos, como as anomalias externas. Baseados neste contexto sensorial descrito na ABNT NBR16747:2020, diversos autores apresentam propostas para validar a inspeção visual uma análise qualitativa subjetiva, com fornecimento de informações quantitativas como por exemplo a qualificação do dano conforme urgência, tendência e gravidade.

\subsection{Analise Sensorial - Tabela GUT}

A tabela GUT (gravidade, urgência e tendência) de Kepner eTregoe apresentada, segundo GOMIDE et al (2011), é a ferramenta que possibilita ao inspetor técnico a organização das ações de correção e priorização das intervenções corretivas a serem propostas no final da inspeção.

De acordo com os estudos de ALVAREZ (1997), a proposta original de Kepner e Tregoe é a tomada de decisão administrativa baseada em três processos de análise: "Análise de Problema (identificação da causa do problema), Análise de Decisão (escolha de uma solução para o problema) e Análise de Problema Potencial (planejamento da implantação da solução)". Uma vez qualificados, todos estes processos podem ser comparados de acordo com os valores finais estabelecidos na analise GUT.

No Brasil GOMIDE et al (2011), adaptaram os reconhecidos estudos da tabela GUT à análise de danos perceptíveis durante a inspeção sensorial. Os autores propõem a calibração dos pesos atribuídos à gravidade, urgência e tendência conforme Quadro 2.

Quadro 2 - Tabela GUT- desenvolvido por KEPNER e TREGOE. Fonte: (GOMIDE; NETO; GULLO, 2011)

\begin{tabular}{|c|c|c|c|c|}
\hline GRAU & GRAVIDADE & URGÊNCIA & TENDÊNCIA & PESO \\
\hline Total & $\begin{array}{l}\text { Perda de vidas humanas, do meio ambiente ou do } \\
\text { próprio edifício }\end{array}$ & Evento em ocorrência & Evolução imediata & 10 \\
\hline Alta & $\begin{array}{l}\text { Ferimentos em pessoas, danos ao meio ambiente } \\
\text { ou ao edifício }\end{array}$ & Evento prestes a ocorrer & $\begin{array}{l}\text { Evolução em curto } \\
\text { prazo }\end{array}$ & 8 \\
\hline Média & $\begin{array}{l}\text { Desconfortos, deterioração do meio ambiente ou } \\
\text { do edifício }\end{array}$ & $\begin{array}{l}\text { Evento prognosticado para } \\
\text { breve }\end{array}$ & $\begin{array}{l}\text { Evolução em médio } \\
\text { prazo }\end{array}$ & 6 \\
\hline Baixa & $\begin{array}{l}\text { Pequenos incômodos ou pequenos prejuízos } \\
\text { financeiros }\end{array}$ & $\begin{array}{l}\text { Evento prognosticado para } \\
\text { adiante }\end{array}$ & $\begin{array}{l}\text { Evolução em longo } \\
\text { prazo }\end{array}$ & 3 \\
\hline Nenhum & Nenhuma & Evento imprevisto & Não vai evoluir & 1 \\
\hline
\end{tabular}

Com a análise visual da manifestação patológica e a degradação percebida, GOMIDE et al (2011) propuseram o grau de dano variando de Total a Nenhum, com explanação textual orientativa. Cada grau de dano possui sua correlação quantitativa pré-estabelecida, conforme pode ser visto no Quadro 2.

\subsection{Metodologia aplicada ao Museu da Cidade}

O Museu da Cidade foi segmentado nos sistemas de acordo com os elementos principais que estão em degradação. Desta assertiva foram vistoriados os seguintes sistemas e seus componentes:

- Sistema Estrutural composto das grandes vigas " $\mathrm{C}$ ", lajes e pilares de concreto que formam o museu.

- Sistema de Impermeabilização composto por todo o sistema de mantas e impermeabilizantes que protegem os elementos estruturais ou revestimentos.

- Sistema Coletores Pluviais responsável pela drenagem até as galerias de esgoto presentes na sarjeta.

- Sistema de Fachadas composto por todo o acervo patrimonial esculpido nas fachadas, incluído a parte de textos cravados no revestimento de mármore.

- Sistema de Esquadrias representa as janelas, portas e brises metálicos que favorecem não só o acesso público como claridade e ventilação do museu.

- Sistema de Pisos abrange o calçamento interno e externo, limitando a área sombreada do monumento uma vez que está inserido na praça dos três poderes.

- Sistema de Tetos são os forros internos parte visível da laje estrutural que compõem o pórtico principal.

- Sistema de Revestimentos Internos é a parte de acabamentos de mármore aplicados na parte interna da estrutura e apresentam o acervo móvel do museu. 
- Sistema de Acessibilidade é inexistente e representa grande limitação ao público pois à época da construção este não fazia parte dos estudos de projetos ou necessidades.

Foi realizada uma inspeção visual no dia sei de novembro de 2020, no período entre 14 e 16 horas. Durante essa inspeção foi possível identificar diversas manifestações patológicas no Museu da Cidade.

Nas fachadas, as peças de mármore apresentam uma grande quantidade de fissuras mapeadas, provavelmente decorrente da retração da argamassa de assentamento, conforme pode ser visto na Figura 7.

A Figura 7 mostra também, que foram identificados alguns pontos com fraturas e lascagem. Essas patologias são meios de entrada de água e impurezas, agravando ou ocasionando novas anomalias, como a lixiviação, que também foi identificada.

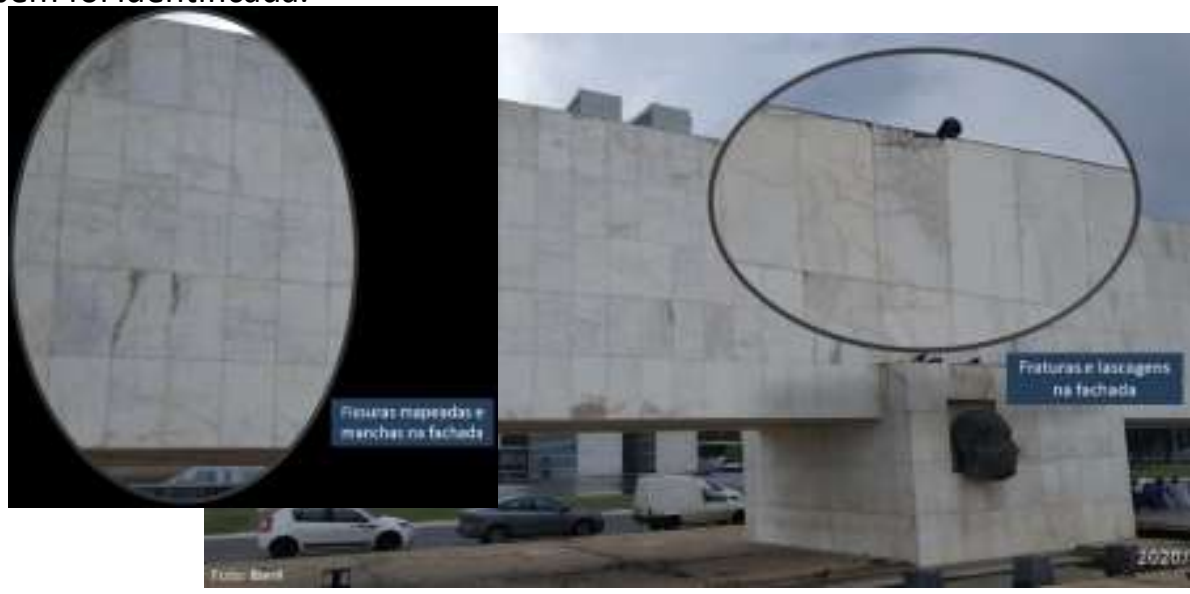

Figura 7 - Manifestações patológicas detectadas na fachada do Museu da Cidade

Também foram observadas manchas por infiltração nas fissuras e em rejuntes comprometidos e alterações cromáticas nas pedras por umidade, insolação, poeira e sujeira (Figura 8). Inicialmente, as manchas irão afetar a estética do edifício e, posteriormente, poderão danificar as propriedades físicas e mecânicas das peças.

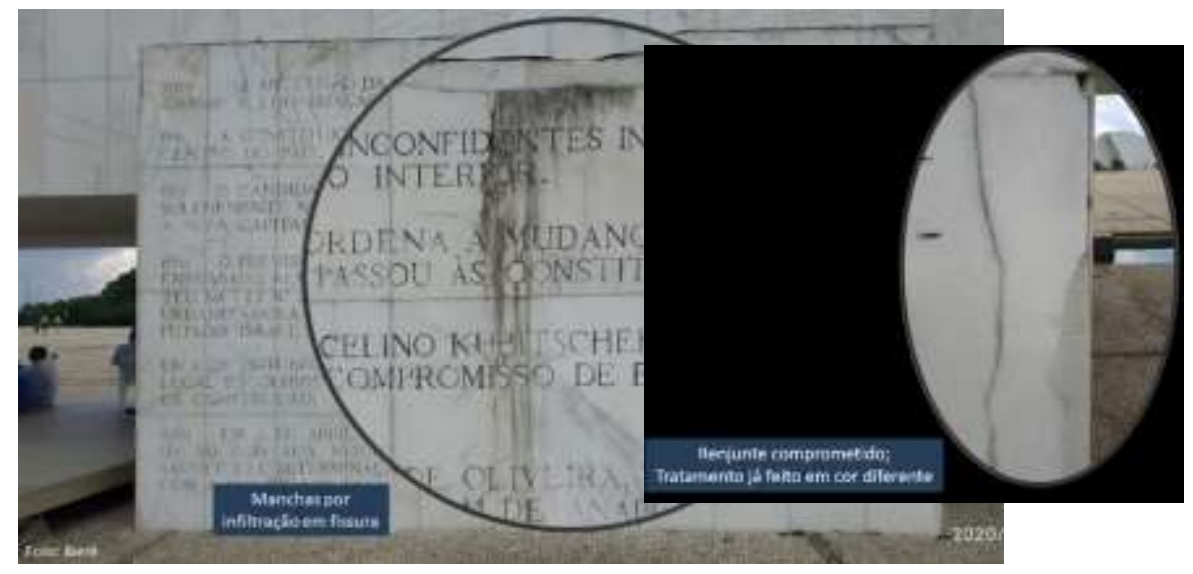

Figura 8 - Manchas por infiltração em fissura

As peças de granito da rampa de entrada apresentam manchas de umidade, fraturas e desplacamento, conforme observado na Figura 9. As pedras do chão estão em várias partes soltas e com crescimento de vegetação. É também identificado o acúmulo de lixo na região. 


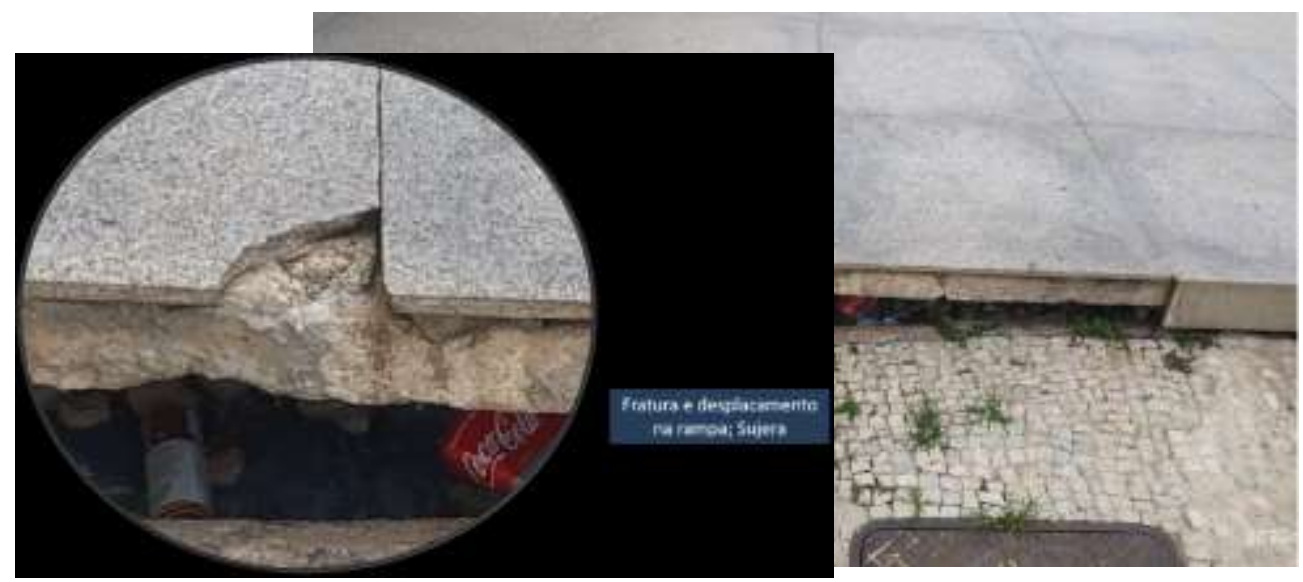

Figura 9 - Fratura e desplacamento na rampa; Sujeira

No interior do Museu são identificadas fissuras nas peças de mármore, fraturas e lascamento, pontos com infiltração, lixiviação, alterações cromáticas, rejuntes comprometidos, pintura dos dizeres com falhas e vários trabalhos de reparo com cores e texturas diferentes (Figura 10). As alterações cromáticas nas peças podem ocorrer por umidade nas peças, impurezas nos assentamentos e algum ponto de corrosão.

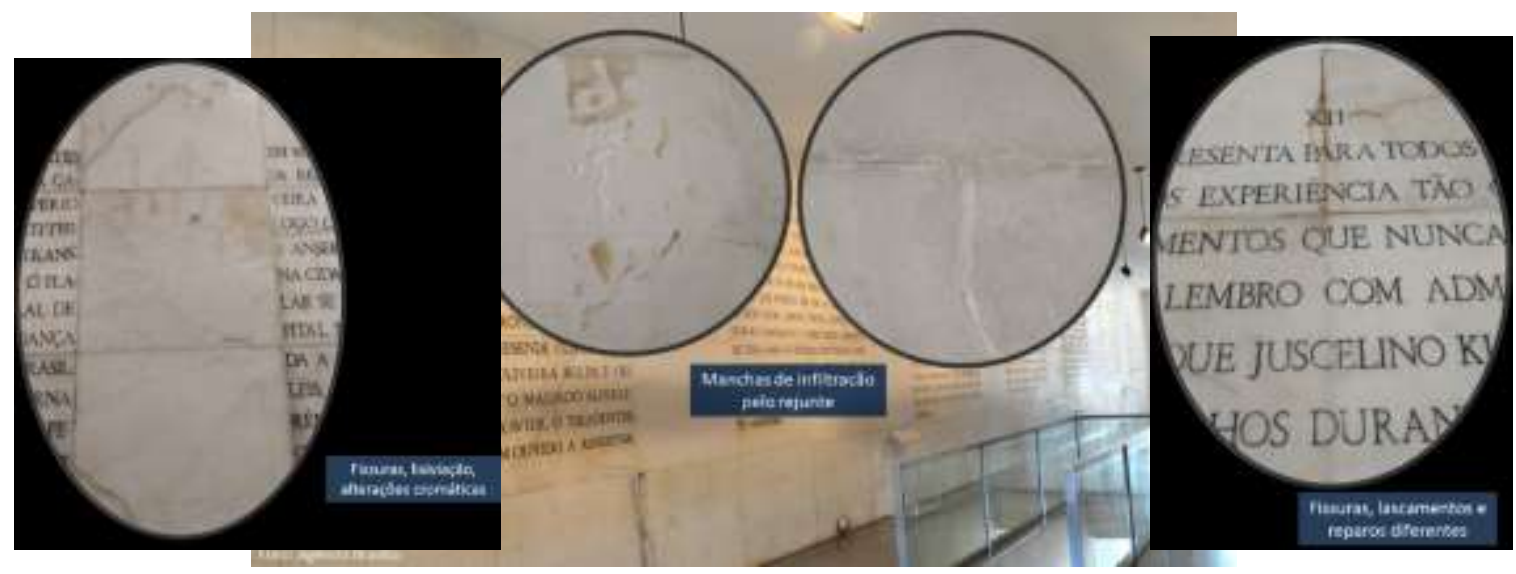

Figura 10 - Manifestações patológicas encontradas no interior do Museu da Cidade

Além disso, as esquadrias das janelas apresentam deterioração, comprometimento em sua vedação e sujeira; no forro há manchas de infiltração e existem diversas caixas de tomadas faltando, com a fiação aparecendo e manchas na peça de mármore ao redor das tomadas também foram identificadas.

A análise da degradação com aplicação da tabela GUT foi registrada durante a inspeção visual e forneceu os dados do Quadro 3.

Quadro 3 - Inspeção no Museu da Cidade - Aplicação da Tabela GUT.

\begin{tabular}{|l|c|c|c|c|}
\hline SISTEMAS & G & U & T & GUT \\
\hline 1.Sistemas Estruturais & M & B & B & $\mathbf{1 4}$ \\
\hline 2.Impermeabilização & A & T & T & $\mathbf{2 8}$ \\
\hline 3. Fachadas & A & A & A & $\mathbf{2 4}$ \\
\hline 4.Coletores Pluviais & A & T & T & $\mathbf{2 8}$ \\
\hline 5.Esquadrias Internas & M & T & M & $\mathbf{2 2}$ \\
\hline 6.Pisos & A & T & A & $\mathbf{2 6}$ \\
\hline 7.Tetos & M & M & A & $\mathbf{2 0}$ \\
\hline 8.Revestimentos internos & M & T & B & $\mathbf{2 0}$ \\
\hline 9.Acessibiliade & T & T & T & $\mathbf{3 0}$ \\
\hline
\end{tabular}

De forma gráfica a Figura 11 apresenta os dados consolidados da inspeção visual, demonstrando que o sistema de acessibilidade desponta como prioridade na ação de reforma ou manutenção. 


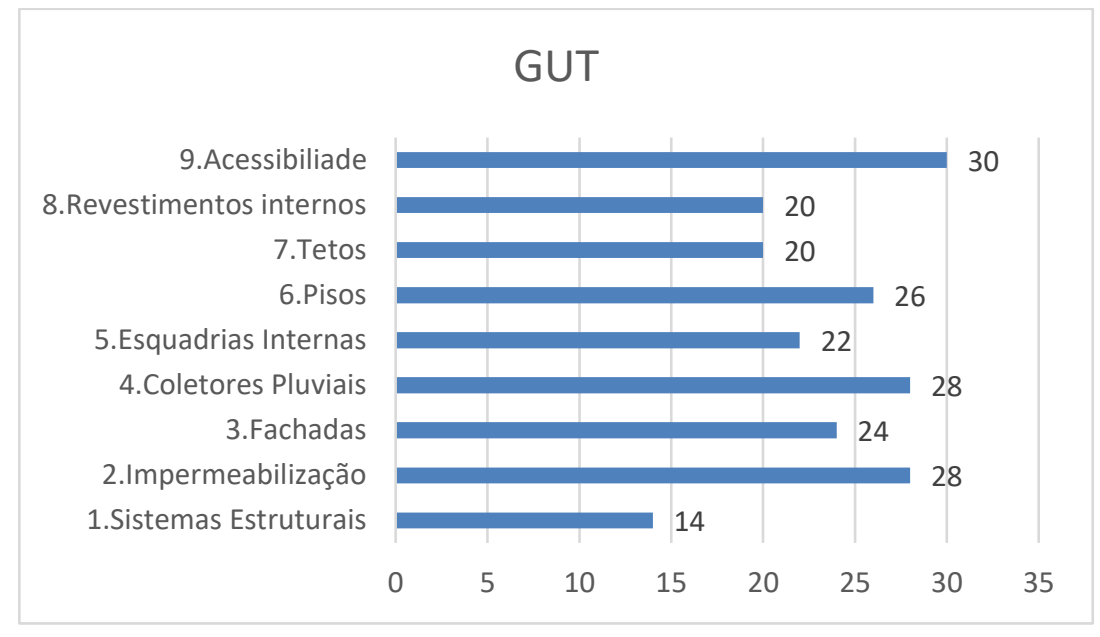

Figura 11 - Análise gráfica da Tabela GUT - Inspeção do Museu as Cidade.

Verifica-se a eficiência da aplicação proposta por Kepner e Tregoe e adaptada por GOMIDE et al (2011), uma vez que é possível estabelecer a ordem de prioridades de intervenção de acordo com o valor GUT obtido. Neste sentido podemos ordenar as ações de reforma no sistema de acessibilidade (GUT=30), seguido por Coletores Pluviais e Impermeabilização (GUT=28) e sucessivamente até o Sistema Estrutural (GUT = 14).

\section{Conclusões}

Ao analisar a estrutura do Museu da Cidade, podemos explorar a importância dele não só como registro histórico da construção de Brasília, mas também sua contribuição para a demonstração das possibilidades do concreto armado exploradas na arquitetura moderna brasileira.

As análises e inspeções realizadas em importantes obras como o Museu da Cidade contribuem para a memória do patrimônio moderno brasileiro, além de expor e traçar diretrizes para sua preservação.

\section{Referências Bibliográficas}

ABNT NBR-16747 (2020). Inspeção predial - Diretrizes, conceitos, terminologia e procedimento. Associação Brasileira de Normas Técnicas, p. 12.

ABNT NBR- 6118 (2014). Projeto de estruturas de concreto - Procedimento. Associação Brasileira de Normas Técnicas.

ABNT NBR-6120 (2000). Cargas para o cálculo de estruturas de edificações. Associação Brasileira de Normas Técnicas.

ALVAREZ, R. dos R. (1997). Métodos de Identificação, Análise e Solução de Problemas: Uma Análise Comparativa. XVII Encontro Nacional de Engenharia de Produção.

GOMIDE, T. L. F.; NETO, J. C. P. F.; GULLO, M. A. (2011). Inspeção Predial Total - Diretrizes e Laudos no Enfoque da Qualidade Total e da Engenharia Diagnóstica. São Paulo-SP.

IPHAN. (2009). Patrimônio no DF: bens tombados. Brasília: Superintendência do Instituto do Patrimônio Histórico e Artístico Nacional no Distrito Federal.

LAUANDE, F. (2010). A Praça dos Três Poderes. Arquitextos Vitruvius, n. 120, ano 10, maio de 2010 [online] Disponível em: <https://vitruvius.com.br/index.php/revistas/read/arquitextos/10.120/3424>. Acesso em 11 Nov. 2020.

NIEMEYER, O. (1959). Museu de Brasília. Revista Módulo, v. 2, n. 12, p. 36-37, Fev. 1959.

SOARES, E. (2017). A narrativa do Museu da Cidade: Brasília inscrita na pedra. V!RUS, São Carlos, n. 15, 2017. [online] Disponível em: <http://www.nomads.usp.br/virus/virus15/?sec=4\&item=7\&lang=pt>. Acesso em: 11 Nov. 2020. 